\title{
Measuring the Efficiency of E-government Websites
}

\author{
A. Basit Darem \\ Research Scholar \\ DoS in Computer Science \\ University of Mysore
}

\author{
Suresha, PhD. \\ Professor \\ DoS in Computer Science \\ University of Mysore
}

\begin{abstract}
The efficiency of e-government websites is a very crucial factor for e-government success. Users prefer sites that allow them to get their tasks done successfully and quickly. In this paper, the efficiency of the current government websites at the local self-government (district level) in India is measured using two different techniques. The techniques used here are related to time and effort. In the time technique, two methods are used, the first method is about the number of successful tasks that take less than average time and the second method is about the number of successful tasks per unit of time (timeon-task). In the effort technique, we calculate the number of successful tasks completed using the optimal path. The results of the experiment conducted to measure the efficiency showed that there is an urgent need to improve the usability of e-government websites in order to be efficient and more beneficial for citizens.
\end{abstract}

\section{Keywords}

E-government, websites, efficiency, time-on-task, effort.

\section{INTRODUCTION}

Nowadays, there are significant numbers of e-governments operating at national and local levels that are accessible via the Internet which provide a variety of online information and services [1]. E-government can be defined as "the use of technology to enhance the access to and delivery of government services to benefit citizens, business partners and employees" [2]. In such an environment, citizens have increasingly been able to interact with e-government by searching for government information and getting government services through websites without time and space limitations. The website works like a channel or window between government and citizens. On the Web, usability is a necessary condition for survival. If a website is difficult to use, people leave it [3]. Moreover, the user will return to the old style of dealing with government face to face or through phone. The result of that will be a huge loss for the government which designed such unusable website.

The international standard (ISO 9241) [4] defined usability as "the extent to which a product can be used by specified users to achieve specified goals with effectiveness, efficiency and satisfaction in a specified context of use". From the above definition effectiveness means "the accuracy and completeness with which users achieve specified goals", efficiency is "the resources expended in relation to the accuracy and completeness with which users achieve goals", and satisfaction is described as "the comfort and acceptability of use".

In the researcher's previous work [5], the effectiveness of egovernment websites was evaluated using usability test experiment. This paper are presented the results of using the same usability test experiment to evaluate the efficiency of the current government websites at the local self-government (district level) in India. The local government is an important part of good governance as most citizens are normally affected more by local governance than by the other layers of governance [6]. Our study will try to find out to what extent these e-government websites in local government in India are efficient and easy to use by the citizens (users). The aim of this evaluation is to better understand how website visitors are using the government websites.

Efficiency is evaluated by the amount of effort (cognitive and physical) required to complete a task [7]. The efficiency is measured using two different techniques, time, and effort.

\subsection{Techniques}

Efficiency is often measured by the number of steps or actions required to complete a task or by the ratio of the task success rate to the average time per task. The main two techniques of measuring the efficiency of websites are illustrated below.

\section{[I] Time Technique}

In usability tests, task times are an often reported usability metric [8]. Efficiency is one of the cardinal aspects of a product's usability [9]. Jeff in [9] states that the amount of time it takes for a user to complete a task is one of the best predictors of efficiency because it:

1. illustrates the slightest variability (in seconds) that is more difficult to detect in other measures like errors;

2. is a continuous measurement meaning it can be subdivided infinitely (unlike task completion which is discrete-binary) and many more statistical tests can be used to detect meaning in the data.

Users prefer sites that allow them to get their tasks done successfully and quickly. Time-on-task (sometimes referred as task completion time or simply task time) is an excellent way to measure the efficiency of any product [7]. The time it takes a participant to perform a task says a lot about the usability of the website. Time-on-task is simply the time elapsed between the start of a task and the end of a task, usually expressed in minutes or seconds. The best way to record time is to use automated technique. It has several advantages, not only it is less error-prone but it's also much less obtrusive [7]. In the time technique, two methods are used. The first method is the number of successful tasks that take less than average time and the second method is the number of successful tasks per unit of time (time-on-task).

a) Method 1 (the number of successful tasks that take less than average time)

Some tasks were inherently more difficult to complete than others were and it is reflected by the average time on task. In this work, the average time is used after removing the outliers as optimal time for doing the task. Time data for all tasks 
(successful and unsuccessful) is included. The reason for including time data for all tasks involves the case where only a small percentage of the participants actually succeeded at a task, but they happened to do so relatively quickly [10]. Most of the people who failed actually spent much longer on the task. In that case, looking at time data for successful tasks only would give a biased view of the times actually spent on the task. Task time has a strong tendency to be positively skewed (Not Normal), with some users taking a long time to complete a task. This arises from the large individual difference in users. Some users encounter problems with an interface or just use computers slower as they complete tasks. A few long task times pull the mean task time up, making it no longer the typical task time. Instead, it overstates the middle value. With a positive skew, however, the arithmetic mean becomes a relatively poor indicator of the center of a distribution due to the influence of the unusually long task times [11]. Furthermore, Cordes [12]demonstrated that the sample median was a biased estimate of the population median for usability test task times. The geometric mean is the best estimate of the center of the population (the median) [11]. The geometric mean provides the most accurate measure of the middle task time for sample sizes less than 25 [9]. The formula for Geometric mean is:

\section{Equation 1}

$$
G M_{\bar{y}}=\sqrt[n]{y_{1} y_{2} y_{3} \ldots y_{n}}
$$

\section{Where $n$ : sample size, $y$ : time value}

The average time spent by the participant for each task was measured, and then the percentage of participants who completed the task successfully in less than the average time (Geometric mean) was calculated. Therefore, to measure the efficiency of the website the number of participants who completed their task successfully in less than average time was helpful. If they are more, for all the tasks, then the website is efficient and vice versa.

The confidence interval (C.I) was calculated for a mean that specifies a range of values within which the unknown population parameter -in this case the mean- may lie[13]. The width of the confidence interval gives some idea about how uncertain one is about the unknown population parameter. A very wide interval may indicate that more data should be collected before anything very definite can be said about the parameter[14]. These intervals for different confidence levels ere calculated, depending on the degree of precision expected. An interval calculated at a 95\% level was interpreted as, 95\% confident that the interval contains the true population mean. It could also be said that $95 \%$ of all confidence intervals formed in this manner (from different samples of the population) will include the true population mean[15].

\section{b) Method 1 (Number of successful tasks per unit of time (time-on-task))}

The Common Industry Format (ISO 9241-11) [4] specifies that task completion rate per unit of time (typically minutes) is one of the core measures of efficiency. Calculating efficiency is to count the number of tasks successfully completed by each participant and divide that by the total time spent by the participant on all the tasks (successful and unsuccessful) [7].

\section{Equation 2}

\section{Efficiency $=($ Number of successful tasks/total time $)$}

If each participant in a usability test attempts the same number of tasks, then this is equivalent to the number of correct tasks per minute that we just discussed. The advantage of this percentage technique is that it also works when the participants are presented with different numbers of tasks. Simply divide each participant's task success rate (percent) by their mean task time in minutes. (Other units of time can be used if needed.) The result is usually expressed as a percentage, although techniqueally it's a percentage per minute. Note that it's possible (and in some studies common) for this percentage to go above $100 \%$ for participants who are very accurate and quick [10].

\section{[II] Effort Technique}

Another way to measure efficiency is to look at the amount of effort required to complete a task. This is typically done by measuring the number of actions or steps that participants took in performing each task. This technique calculated the amount of effort required to complete a task [7]. It looks only to the successful tasks. The reason for using only successful task is related to those users who failed to complete the task. It may be that the visited pages were lesser than in the optimal path, thus their efficiency will be more than those who succeed in the task.

The formula to calculate effort is:

\section{Equation 3}

Where O: optimal path,

$$
\text { Effort }=O / N
$$

$\mathrm{N}$ : Number of pages viewed in each task (for successful task).

\section{EXPERIMENTAL SETUP}

Part of the results of this usability test experiment has been used in previous work of the researchers [5] to measure the effectiveness of e-government websites. Other part of the data from the same experiment are used here, so the same experiment setup is used. To avoid unreliable and biased results, the design of a user test evaluation and its execution should be carefully planned and managed. The researcher followed the framework proposed in the literature [12],[7]-[10] to conduct the usability test and collect the data. The framework has the following steps, 1) define the goals of the test, 2) define the user sample to participate in the test, 3) select tasks and scenarios, 4) define how to measure usability, 5) prepare the material and the experimental environment.

Each individual session will consist of a set of tasks and a questionnaire for the participants to complete. The individual evaluations will take place in the following order, a) a performance evaluation in which each participant is asked to perform a series of real-life tasks, b) a questionnaire after each performance evaluation to gather additional insights from the participants about Mysore District's website.

\subsection{Participants:}

Typically, the test was conducted with a group of potential users who have knowledge of computer and internet. Fourteen participants ( 2 female, 12 male) in the age group ranging from 
20 to 30 years volunteered for this domain study. All participants were familiar with the use of Internet (average experience of internet use was 3 years).

\subsection{Evaluation Tasks:}

The tasks were intended to be general, simple, and from the reality of citizens' daily needs. Test participants attempted completion of the tasks as shown in Table 1.

Table 1 Tasks Attempted

\begin{tabular}{|c|l|}
\hline No & Task description \\
\hline Task 1 & Find important centers of learning in Mysore. \\
\hline Task 2 & Download the application form of birth registration. \\
\hline Task 3 & $\begin{array}{l}\text { Find the page that gives information about tourist } \\
\text { places in Mysore. }\end{array}$ \\
\hline Task 4 & Find the Public Grievance System. \\
\hline Task 5 & $\begin{array}{l}\text { Find the contact details of Karnataka Urban Water } \\
\text { Supply and Drainage Board. }\end{array}$ \\
\hline
\end{tabular}

\subsection{Procedure:}

Users were asked to complete a series of routine tasks. Sessions were recorded and analyzed to identify the success rate, give-up rate, time spent on task, number of pages visited per task, etc. Mysore district website (www.mysore.nic.in) was selected for this test. It serves as an information gateway to Mysore district citizens to get information and services. An online usability test was conducted using a live version of www.mysor.nic.in located on the internet. Loop11 online tool (avilable in www.loop11.com ) was used to capture the participant's comments, navigation path, heat map, overall satisfaction ratings, questions and feedback. A usability test was intended to determine the extent to which an interface facilitates a user's ability to complete routine tasks.

\subsection{Data Collection:}

The data were collected in an excel file. The first round after exporting the data is to prepare the data for analysis. The second round is filtering the data. The filter was used to check the data against the participants who were not serious and completed the test without care. For that we put some criteria and a threshold. The threshold used for the time spent in task is less than 5 seconds and for the page viewed is 1 page per task. The Filter used was:

if (Visited Pages $=1$ and the Time spent $<5 \mathrm{sec}$ ) for more than 2 tasks, then the participant is considered not serious, delete the participant's data

By implementing the above filter, the data of participant number 10 was deleted and not included in the final analysis. He spent 2 seconds in each page and visited only 1 page per task. It means that he only navigates through the test by clicking the next button only. The total number of participants included in the final analysis was 14 . They were coded as $\mathrm{p} 1$ to $\mathrm{p} 14$.

\subsection{Data Scoring:}

The data was scored, using the approach found in the literature [7]. A task was counted as a "Success" if the participant was able to achieve the correct outcome, without assistance, within the time allotted on a per task basis. The total number of successes were calculated for each task and then divided by the total number of times that task was attempted. The results are provided as a percentage. If the participant abandoned (gave-up) the task, did not reach the correct answer, or performed it incorrectly, the task was counted as a "Failure." The time was calculated in seconds. The number of visited pages was recorded.

\section{RESULT AND DISCUSSION}

In this section, the results are presented starting from the time and how it is manipulated, and then time-on-tasks and the effort techniques are used to measure the efficiency to find if the website is efficient.

\subsection{Time}

\section{a. Number of successful tasks that take less than average time}

To measure the tendency the mean or Median was used. Table 2 shows the different means of the time spent by the participant in each task before removing the outlier. In case of Task 1, the difference can be seen between the Athematic mean (137.4 seconds), Geometric mean (89.4 seconds) and the Median (80.5 seconds). The variance was measured using standard deviation $(\mathrm{SD}=127.1)$. The confident interval (C.I) is 66.6 seconds.

Table 2 The different means of the time spent by the participants in each task

\begin{tabular}{|c|c|c|c|c|c|}
\hline Participants & Task 1 & Task 2 & Task 3 & Task 4 & Task 5 \\
\hline P 1 & 78 & 104 & 16 & 19 & 92 \\
\hline P 2 & 83 & 111 & 53 & 68 & 114 \\
\hline P 3 & 68 & 269 & 158 & 82 & 262 \\
\hline P 4 & 160 & 139 & 45 & 138 & 98 \\
\hline P 5 & 451 & 59 & 19 & 138 & 175 \\
\hline P 6 & 59 & 34 & 34 & 43 & 44 \\
\hline P 7 & 41 & 23 & 8 & 5 & 6 \\
\hline P 8 & 485 & 9 & 69 & 292 & 143 \\
\hline P 9 & 124 & 107 & 60 & 249 & 155 \\
\hline P 10 & 148 & 219 & 83 & 220 & 238 \\
\hline P 11 & 137 & 119 & 56 & 17 & 67 \\
\hline P 12 & 18 & 120 & 57 & 20 & 93 \\
\hline P 13 & 31 & 10 & 11 & 32 & 21 \\
\hline P 14 & 40 & 30 & 27 & 14 & 5 \\
\hline Athematic mean & 137.4 & 96.6 & 49.7 & 95.5 & 108.1 \\
\hline Geometric mean & 89.4 & 63.7 & 37.3 & 52.0 & 67.8 \\
\hline Median & 80.5 & 105.5 & 49.0 & 55.5 & 95.5 \\
\hline ST DV & 127.1 & 74.5 & 37.7 & 85.0 & 79.7 \\
\hline Max & 485.0 & 269.0 & 158.0 & 292.0 & 262.0 \\
\hline Min & 18.0 & 9.0 & 8.0 & 5.0 & 5.0 \\
\hline Confidence Interval & 66.6 & 39.0 & 19.7 & 44.5 & 41.8 \\
\hline 95\%) & & & & & \\
\hline
\end{tabular}

Moreover, the range (the distance between the minimum and maximum data points) is relatively high (467 seconds). The above results showed that these data need to be filtered and cleaned to remove the outlier data before proceeding any further or calculating the data. The scatter plot was used to identify points distant from the normal scattering. The outliers were removed based on the following condition "if the time recorded for the participant in the task is greater than double the arithmetic average, the data should be removed". Then the Geometric Means, SD, and CI were calculated. Figure 1 (a,b,c and e) illustrates the time distribution for each task. The outliers can be figured out easily. 


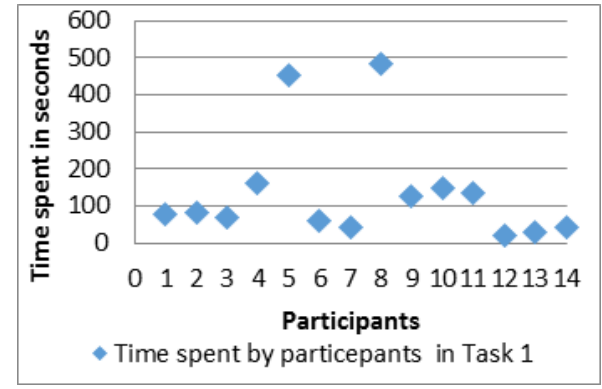

a. Task 1

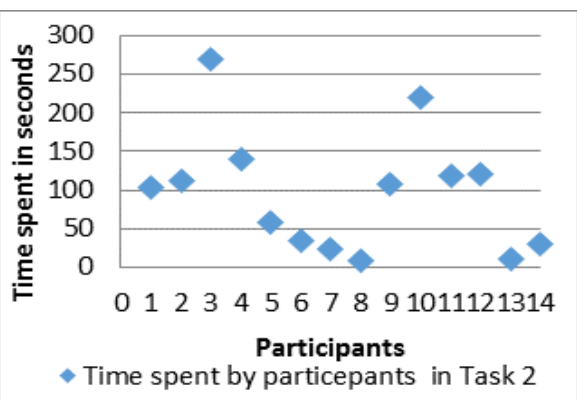

b. Task 2

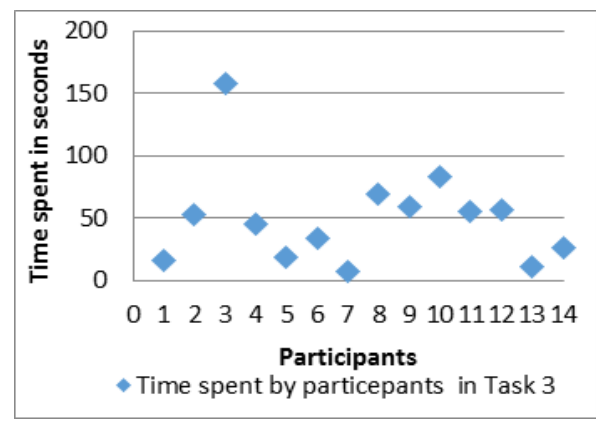

c. Task 3

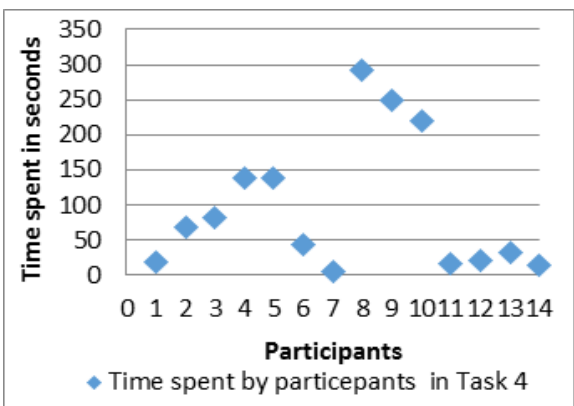

\section{d. Task 4}

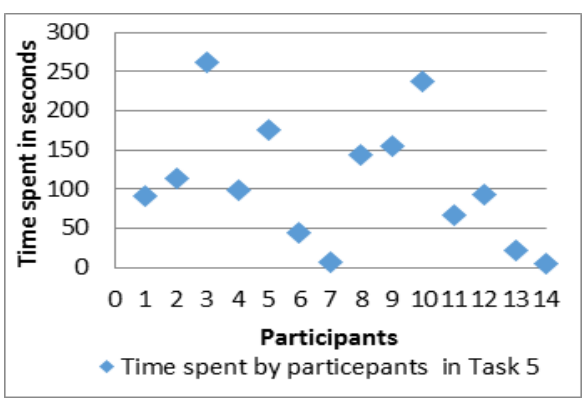

e. Task 5

Figure 1 (a,b,c,d, and e) time spent by participant in each task
Table 3 shows the different means of the time spent by the participants in each task after removing the outlier. The place of the removed data is treated as missing value. In case of Task 1, the difference between the Athematic mean ( 82.3 seconds), Geometric mean (67.9 seconds) and Median (73 seconds) can be observed. The standard deviation (SD) is 48.1. Moreover, the range (the distance between the minimum and maximum data points) becomes low 142 seconds compared to 467 seconds before cleaning the data. C.I with (95\%) confidence level is relatively small (29.8) compare to 66.6 before removing the outliers. It reduced by more than $50 \%$ to give better result.

Table 3 The different means of the time spent by participants in each task after removing the outlier

\begin{tabular}{|c|c|c|c|c|c|}
\hline Participants & Task & Task & Task & Task & Task \\
\hline P 1 & $\mathbf{1}$ & $\mathbf{2}$ & $\mathbf{3}$ & $\mathbf{4}$ & $\mathbf{5}$ \\
\hline P 2 & 78 & 104 & 16 & 19 & 92 \\
\hline P 3 & 83 & 111 & 53 & 68 & 114 \\
\hline P 4 & 68 & & & 82 & \\
\hline P 5 & 160 & 139 & 45 & 138 & 98 \\
\hline P 6 & & 59 & 19 & 138 & 175 \\
\hline P 7 & 59 & 34 & 34 & 43 & 44 \\
\hline P 8 & 41 & 23 & 8 & 5 & 6 \\
\hline P 9 & & 9 & 69 & & 143 \\
\hline P 10 & 124 & 107 & 60 & & 155 \\
\hline P 11 & 148 & & 83 & & \\
\hline P 12 & 137 & 119 & 56 & 17 & 67 \\
\hline P 13 & 18 & 120 & 57 & 20 & 93 \\
\hline P 14 & 31 & 10 & 11 & 32 & 21 \\
\hline & 40 & 30 & 27 & 14 & 5 \\
\hline mean & 82.3 & 72.1 & 41.4 & 52.4 & 84.4 \\
\hline Athematic & 67.9 & 50.9 & 33.4 & 33.8 & 54.5 \\
\hline Geometric mean & 73 & 81.5 & 45 & 32 & 92.5 \\
\hline Median & 48.1 & 49.0 & 24.0 & 48.4 & 51.5 \\
\hline ST DV & 160 & 139 & 83 & 138 & 175 \\
\hline Max & 18 & 9 & 8 & 5 & 5 \\
\hline Min & 29.8 & 27.7 & 13.0 & 28.6 & 31.9 \\
\hline Confidence Interval (95\%)
\end{tabular}

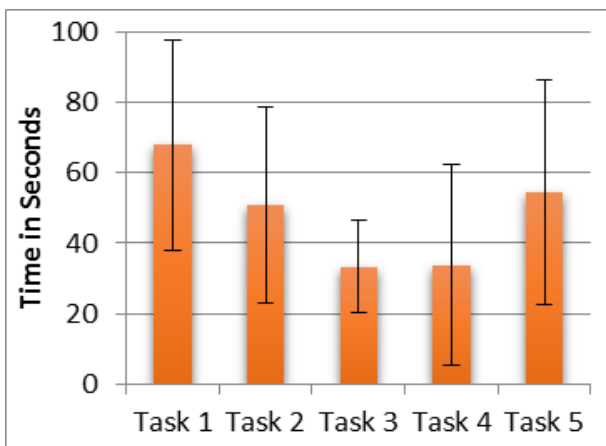

Figure 2 Geometric means after cleaning unwanted data (Error bars represent a 95\% confidence interval for the mean)

Figure 2 shows the Geometric means after cleaning unwanted data to represent the optimal time for doing each task. Table 4 shows the success rate for all participants. The success rates for each task are $50 \%$ for Task $1,64 \%$ for Task 3, 57\% for Task 4 and $0 \%$ for Task 2 and Task 5 . The average success rate for the website is relatively very low $(34 \%)$. Figure 3 shows the Participants who successfully completed the task in less than average time for each task. Only four participants completed successfully four tasks in less than average time for the respective task. 
The average success rate for the tasks that take less than average time of each task is $5.6 \%$ only. The result indicates that this website is time consuming. The user needs to spend more time to get his work done. This finding leads to the conclusion that this website is not efficient.

\begin{tabular}{|c|c|c|c|c|c|}
\hline & \multicolumn{5}{|c|}{ Table 4 Success result } \\
\hline \multirow[b]{2}{*}{ Participants } & \multicolumn{5}{|c|}{ Task result ( (0 Fail, 1 Success) } \\
\hline & \begin{tabular}{|c} 
Task \\
\end{tabular} & $\begin{array}{c}\text { Task } \\
2\end{array}$ & $\begin{array}{c}\text { Task } \\
3\end{array}$ & $\begin{array}{c}\text { Task } \\
4\end{array}$ & $\begin{array}{c}\text { Task } \\
5\end{array}$ \\
\hline P 1 & 1 & 0 & 1 & 1 & 0 \\
\hline P 2 & 1 & 0 & 1 & 1 & 0 \\
\hline P 3 & 1 & 0 & 1 & 1 & 0 \\
\hline P 4 & 1 & 0 & 1 & 1 & 0 \\
\hline P 5 & 0 & 0 & 0 & 0 & 0 \\
\hline P 6 & 0 & 0 & 1 & 0 & 0 \\
\hline P 7 & 0 & 0 & 0 & 0 & 0 \\
\hline P 8 & 0 & 0 & 1 & 1 & 0 \\
\hline P9 & 1 & 0 & 1 & 1 & 0 \\
\hline P 10 & 0 & 0 & 0 & 1 & 0 \\
\hline P 11 & 1 & 0 & 1 & 0 & 0 \\
\hline P 12 & 1 & 0 & 1 & 1 & 0 \\
\hline P 13 & 0 & 0 & 0 & 0 & 0 \\
\hline P 14 & 0 & 0 & 0 & 0 & 0 \\
\hline Average & $50 \%$ & $0 \%$ & $64 \%$ & $57 \%$ & $0 \%$ \\
\hline
\end{tabular}

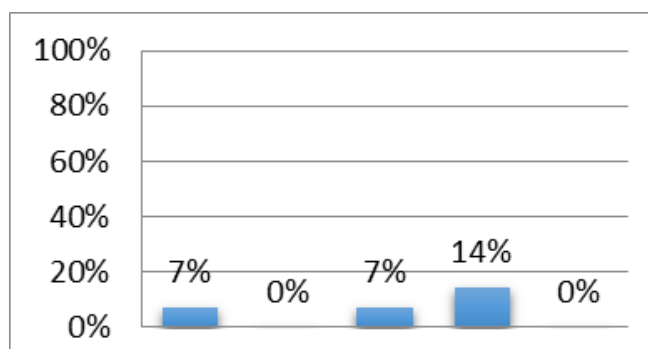

Task 1 Task 2 Task 3 Task 4 Task 5

Figure 3 Participants who successfully completed task in less than average time of each task

\section{a. Number of successful tasks per unit of time}

Table 5 Efficiency using time on task method for all the Participants

\begin{tabular}{|c|c|c|c|c|}
\hline \multirow{2}{*}{ Participants } & \multicolumn{2}{|c|}{$\begin{array}{c}\text { Total time taken } \\
\text { on all tasks }\end{array}$} & \multirow{2}{*}{$\begin{array}{c}\text { No of } \\
\text { successfully } \\
\text { completed } \\
\text { Tasks } \\
\end{array}$} & \multirow{2}{*}{$\begin{array}{c}\text { Efficiency (No } \\
\text { of Success } \\
\text { Task/ time on } \\
\text { tasks) }\end{array}$} \\
\hline & Seconds & Minutes & & \\
\hline P 1 & 309 & 5.15 & 3 & $58 \%$ \\
\hline P 2 & 429 & 7.15 & 3 & $42 \%$ \\
\hline P 3 & 839 & 13.98 & 3 & $21 \%$ \\
\hline $\mathrm{P} 4$ & 580 & 9.67 & 3 & $31 \%$ \\
\hline P 5 & 842 & 14.03 & 0 & $0 \%$ \\
\hline P 6 & 214 & 3.57 & 1 & $28 \%$ \\
\hline P 7 & 83 & 1.38 & 0 & $0 \%$ \\
\hline P 8 & 998 & 16.63 & 2 & $12 \%$ \\
\hline P 9 & 695 & 11.58 & 3 & $26 \%$ \\
\hline P 10 & 908 & 15.13 & 1 & $7 \%$ \\
\hline P 11 & 396 & 6.60 & 2 & $30 \%$ \\
\hline P 12 & 308 & 5.13 & 3 & $58 \%$ \\
\hline P 13 & 105 & 1.75 & 0 & $0 \%$ \\
\hline P 14 & 116 & 1.93 & 0 & $0 \%$ \\
\hline Average & 487.3 & 8.12 & & $22 \%$ \\
\hline
\end{tabular}

Table 5 and Figure 4 show the results of efficiency for all the participants. Two participants recorded $58 \%$ of efficiency with 3 successful tasks in around 5.15 minutes, on the other side four participants failed in all the tasks. By computing the average efficiency for all the participants, it was $22 \%$. This value represents the efficiency of this website using time-ontask method. The participants spend more time to get their work done or they fail to do so. For that, it shows low efficiency.

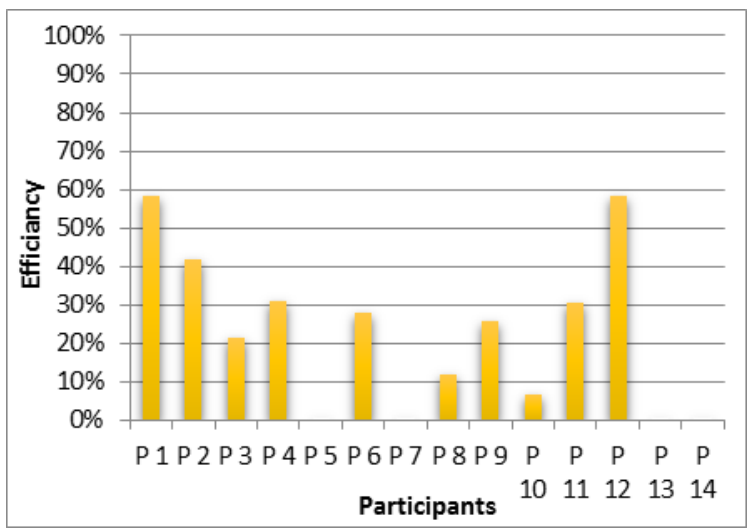

Figure 4 Efficiency using time on task method for all the Participants

\subsection{Effort}

The effort measured only the successful tasks to find out how much effort was spent to attain success. The failed tasks were excluded to avoid bias. The effort for the tasks that had no success rate could not be measured, so it was left empty. Table 6 shows the optimal path that has been calculated by exploring the website and finding out the shortest path to be the optimal path.

\section{Table 6 Optimal path}

\begin{tabular}{|c|c|c|c|c|c|}
\hline Tasks & Task 1 & Task 2 & Task 3 & Task 4 & Task 5 \\
\hline No of pages & 2 & 4 & 2 & 2 & 2 \\
\hline
\end{tabular}

Table 7 shows the page clicked for each task per participant. Task 5 has the highest rate with four pages and Task 1 has the least pages with 2 pages. Table 8 shows the effort in task for all the experiments. The effort in Task 2 and Task 3, could not be calculated because the success rate was zero.

Table 7 The pages viewed per task for all Participants

\begin{tabular}{|c|c|c|c|c|c|c|}
\hline Participants & Task & Task & Task & Task & Task & $\begin{array}{c}\text { Average pages } \\
\text { viewed per } \\
\text { Participants }\end{array}$ \\
\hline P 1 & 2 & 5 & 2 & 3 & 3 & 3 \\
\hline P 2 & 2 & 6 & 4 & 3 & 4 & 3.8 \\
\hline P 3 & 2 & 8 & 10 & 3 & 13 & 7.2 \\
\hline P 4 & 2 & 4 & 2 & 5 & 1 & 2.8 \\
\hline P 5 & 1 & 1 & 1 & 1 & 1 & 1 \\
\hline P 6 & 2 & 1 & 2 & 3 & 3 & 2.2 \\
\hline P 7 & 1 & 1 & 1 & 1 & 1 & 1 \\
\hline P 8 & 4 & 1 & 2 & 7 & 3 & 3.4 \\
\hline P 9 & 2 & 5 & 3 & 4 & 9 & 4.6 \\
\hline P 10 & 5 & 7 & 6 & 6 & 11 & 7 \\
\hline P 11 & 2 & 4 & 3 & 4 & 3 & 3.2 \\
\hline P 12 & 2 & 2 & 4 & 3 & 3 & 2.8 \\
\hline P 13 & 1 & 1 & 1 & 1 & 1 & 1 \\
\hline P 14 & 1 & 2 & 2 & 1 & 1 & 1.4 \\
\hline $\begin{array}{c}\text { Average } \\
\text { pages viewed } \\
\text { per task }\end{array}$ & 2.1 & 3.4 & 3.1 & 3.2 & 4.1 & 3.2 \\
\hline
\end{tabular}


The effort was calculated by dividing the optimal path $(\mathrm{O})$ by $(\mathrm{N})$ the number of pages viewed in each task (for successful task only).

Table 8 The effort for the successful task

\begin{tabular}{|c|c|c|c|c|c|}
\hline Participants & $\begin{array}{c}\text { Task } \\
\mathbf{1}\end{array}$ & $\begin{array}{c}\text { Task } \\
\mathbf{2}\end{array}$ & $\begin{array}{c}\text { Task } \\
\mathbf{3}\end{array}$ & $\begin{array}{c}\text { Task } \\
\mathbf{4}\end{array}$ & $\begin{array}{c}\text { Task } \\
\mathbf{5}\end{array}$ \\
\hline P 1 & 0 & & 0 & 0.33 & \\
\hline P 2 & 0 & & 0.5 & 0.33 & \\
\hline P 3 & 0 & & 0.8 & 0.33 & \\
\hline P 4 & 0 & & 0 & 0.60 & \\
\hline P 5 & & & & & \\
\hline P 6 & & & 0 & & \\
\hline P 7 & & & & & \\
\hline P 8 & & & 0 & 0.71 & \\
\hline P 9 & 0 & & 0.33 & 0.50 & \\
\hline P 10 & & & & 0.77 & \\
\hline P 11 & 0 & & 0.33 & & \\
\hline P 12 & 0 & & 0.50 & 0.33 & \\
\hline P 13 & & & & & \\
\hline P 14 & & & 0.273 & 0.49 & \\
\hline Average & $\mathbf{0 . 0 0}$ & & $\mathbf{0 . 2 7}$ & $\mathbf{0 . 4 9}$ & \\
\hline
\end{tabular}

The optimal path is the shortest path to the target page or the least number of clicked URL to visited pages to reach the target page that have the required information or services. The results in this formula ranged from (0 to 1$), 1$ means no effort. So, to give more sense to the results, the result was subtracted from 1; now if the result is 0 it means normal effort, but if it is more than 0 there is an up-normal effort, the more the value the more the effort required. For the tasks that didn't have success rate (Task 1 and Task 5) the effort was considered as 1. The average for all the tasks was calculated to find the result of the average effort that could be spent in this website; it was 0.55 .

\section{Summary of Data:}

In general, it was found that the website mysore.nic.in is unclear, not straightforward, and not easy to use. The test identified many major problems including the lack of categorization of topics on the home page, confusion over apparent duplicative usage of some terms, and confusion of terms and abbreviations. The users found many orphan pages, they could not return to home or previous page, the site index or site map does not exist, and there is lack of color contrast between text and background. Moreover no search facility, help or FAQ page were avilable.

\section{CONCLUSION}

In this paper, the efficiency of e-government websites was measured. Different techniques and methods for measuring the efficiency were highlighted. The efficiency was measured using two different techniques, time and effort. The time technique recorded very low efficiency score of 5.6\% from the first method and $22 \%$ from the second method. The website recorded higher effort rate $(.55 \%)$ required than normal effort for navigation and searching for information or services. It is not necessary to use all the techniques and methods mentioned in this paper to measure the efficiency.
Moreover, it is not important for the output of all the techniques to be equal or getting the same value or result. The website needs to be redesigned and improved to achieve better usability score, and to help users to use the website and navigate through easily.

\section{REFERENCES}

[1] Gil-Garcia, J. R. \& Martinez-Moyano, I. J. (2007) Understanding the evolution of e-government: The influence of systems of rules on public sector dynamics, Government Information Quarterly, Vol. 24, 2, pp.266-290.

[2] Deloitte and Touche, 2003. "At the Dawn of eGovernment: The Citizen as Customer." Available from http://www.publicnet.co.uk/publicnet/fe000620.htm; Internet; accessed on January 9, 2003.

[3] Nielsen J., Usability 101 (2012): Usability 101: Introduction to Usability. http://www.nngroup.com/articles. Last access 18-042013.

[4] ISO (1997) ISO 9241: Ergonomics Requirements for Office Work with Visual Display Terminal (VDT) Parts $1-17$.

[5] Basit, A.D., \& Suresha. Experimental evaluation of effectiveness of e-government websites. The International Journal of Emerging Technology and Advanced Engineering (ISSN 2250-2459, 2(11). (2012). P (469-473).

[6] Basit, A.D., Suresha \& Al-Hashmi, A. (2011) Evaluation of the Use of Local Government Websites: Internet Users' Perspective. The IUP Journal of Information Technology, 7(2), 47-55.

[7] Tullis, T., \& Albert, W. (2008). Measuring the user experience: collecting, analyzing, and presenting usability metrics. Amsterdam: Elsevier/Morgan Kaufmann Publishers.

[8] Sauro, J. \& Lewis J. R Correlations among Prototypical Usability Metrics: Evidence for the Construct of Usability. In Proc CHI 2009 (pp. 1609-1618).

[9] Jeff Sauro. "Measuring \& Analyzing Task Times “ September 17, 2004. Avilable at www.measuringusability.com/task_times.html last access 18-04-2013.

[10] Albert, B., Albert, W., Tullis, T., \& Tedesco, D. (2010). Beyond the Usability Lab: Conducting Largescale User Experience Studies. Morgan Kaufmann.

[11] Sauro, J. \& Lewis J. R Average Task Times in Usability Tests: What to Report?. In Proc CHI 2010 (pp. 16091618).

[12] Cordes, $\mathrm{R}$ The effects of running fewer subjects on timeon-task measures. International Journal of HumanComputer Interaction, 5(4), (1993) 393-403.

[13] Cox D.R., Hinkley D.V. (1974) Theoretical Statistics, Chapman \& Hall, p49, p209

[14] Kendall, M.G. and Stuart, D.G. (1973) The Advanced Theory of Statistics. Vol 2: Inference and Relationship, Griffin, London. Section 20.4 
[15] Neyman, J. (1937). "Outline of a Theory of Statistical Estimation Based on the Classical Theory of Probability". Philosophical Transactions of the Royal Society of London A 236: 333-380.

\section{ACKNOWLEDGMENT}

We would like to thank the software producers of Loop11 for the free use of their useful product as well as the participants in this study. 